\title{
Helicobacter pylori Treatment: Potential for Gastric Cancer Prevention
}

\author{
Mostafa Ibrahimi, ${ }^{1}$ Maryam Alaei, ${ }^{1}$ Mohammad-Ali Gholampour, ${ }^{2}$ and Milad \\ Mohammdoo-Khorasani ${ }^{1, *}$ \\ ${ }^{1}$ Department of Clinical Biochemistry, Faculty of Medical Sciences, Tarbiat Modares University, Tehran, Iran \\ ${ }^{2}$ Department of Hematology and Blood Banking, Faculty of Medical Sciences, Tarbiat Modares University, Tehran, Iran \\ "Corresponding author: Milad Mohammdoo-Khorasani, Department of Clinical Biochemistry, Faculty of Medical Sciences, Tarbiat Modares University, Tehran, Iran. E-mail: \\ milad.kh@modares.ac.ir \\ Received 2017 January 07; Accepted 2017 January 14.
}

Keywords: H. pylori, Screening, Gastric Cancer

\section{Dear Editor,}

Helicobacter pylori (H. pylori), a Gram-negative bacterium, which colonizes in the gastric mucosa, was discovered in 1984 and was found to be associated with peptic ulcer disease (1). Almost half of the world's population has been infected with H. pylori, particularly in developing countries where people are more susceptible to the infection, mostly due to the large populations and poor sanitation $(2,3)$.

H. pylori infection occurs during childhood mostly before 5 years of age. Despite severe immune responses and acidic environment of gastric mucosa, bacteria survive in most occasions. Furthermore, without proper combination antibiotic treatment, these bacteria can live in the host for a lifetime. Survival of bacteria inside the host is mainly related to the local change in acidity through inhibition of acid secretion in the host. In addition, the urease activity of $H$.pylori neutralizes gastric acidity by generating ammonium.

H. pylori infection leads to complications, ranging from gastritis to different types of gastric cancer (4). Gastric cancer, as the fourth most common cancer, accounts for onethird of cancer-related deaths. Moreover, it has remained one of the public health issues worldwide. In view of the insidious progression of gastric cancer, most cases are diagnosed in advanced stages; therefore, only less than 30\% of the patients survive more than 5 years, which indicates the significance of screening programs.

Gastric cancer was the leading cause of more than 700 000 deaths in 2012 (5). According to the histological classification, gastric cancer is categorized into diffused and intestinal or cardia and noncardia types, based on its location (6). Different risk factors, including genetic factors, have been associated with gastric cancer. Moreover, poly- morphisms in interleukin-1 $\beta$ and tumor necrosis factor$\alpha$ are considered significant. However, it should be mentioned that environmental factors such as high salt intake and low level of iron could be also effective.

H. pylori is known as a class I carcinogen and is recognized as the most important risk factor for gastric cancer, responsible for more than $75 \%$ of gastric cancer cases $(4,7)$. The mechanism through which $H$. pylori infection leads to gastric cancer remains to be clarified; however, the inflammation caused by $H$. pylori infection predisposes patients to atrophic gastritis, which can progress to precancerous lesion (8).

Cytotoxic antigen (CagA, which forms a secretion system) and vacuolisation protein (VacA) are 2 pathogenic proteins of $H$.pylori, which have been identified to increase the risk of gastric cancer $(9,10)$. Epigenetic changes in epithelial cells, for instance, DNA methylation and histone modification induced by H. pylori infection, also lead to gastric cancer progression (11).

H. pylori is the most important risk factor for gastric cancer; therefore, there are promising assumptions for cancer prevention by means of $H$. pylori treatment. Different studies on many populations have demonstrated the remarkable association between the decreased rate of $H$. pylori infection and reduced incidence of gastric cancer (5). Therefore, based on international guidelines, high-risk populations are suggested to be screened and treated for H. pylori infection (3), although recent investigations have shown that $H$. pylori screening and eradication could be costly, even in low-risk populations $(12,13)$.

The prevalence of $H$. pylori infection has been reported to be exceedingly high among Iranians (94\% and 83\% for noncardia and cardia gastric cancer, respectively) (14). On the other hand, gastrointestinal cancer accounts for al- 
most half of cancer cases, and gastric cancer has the second highest incidence rate among all types of cancer in Iran (15).

In conclusion, according to recent studies, $H$. pylori screening and treatment in highly susceptible populations could be an effective effort to prevent the incidence and mortality of gastric cancer.

\section{References}

1. Malfertheiner P, Megraud F, O'Morain CA, Atherton J, Axon AT, Bazzoli F, et al. Management of Helicobacter pylori infection-the Maastricht IV/ Florence Consensus Report. Gut. 2012;61(5):646-64. doi: 10.1136/gutjnl-2012-302084. [PubMed: 22491499].

2. Mentis A, Lehours P, Megraud F. Epidemiology and Diagnosis of Helicobacter pylori infection. Helicobacter. 2015;20 Suppl 1:1-7. doi: 10.1111/hel.12250. [PubMed: 26372818].

3. Laird-Fick HS, Saini S, Hillard JR. Gastric adenocarcinoma: the role of Helicobacter pylori in pathogenesis and prevention efforts. Postgraduate Med J. 2016.

4. Wroblewski LE, Peek RM, Coburn LA. The Role of the Microbiome in Gastrointestinal Cancer. Gastroenterol Clin North Am. 2016;45(3):54356. doi: 10.1016/j.gtc.2016.04.010. [PubMed: 27546848].

5. Hoed CM, Kuipers EJ. Gastric Cancer: How Can We Reduce the Incidence of this Disease? Current gastroenterology reports. 2016;18(7):1-8.

6. Lauren P. The Two Histological Main Types of Gastric Carcinoma: Diffuse and So-Called Intestinal-Type Carcinoma. An Attempt at a Histo-Clinical Classification. Acta Pathol Microbiol Scand. 1965;64:3149. [PubMed: 14320675$]$.
7. Plummer M, Franceschi S, Vignat J, Forman D, de Martel C. Global burden of gastric cancer attributable to Helicobacter pylori. Int J Cancer. 2015;136(2):487-90. doi: 10.1002/ijc.28999. [PubMed: 24889903].

8. Venerito M, Selgrad M, Malfertheiner P. Helicobacter pylori: gastric cancer and extragastric malignancies - clinical aspects. Helicobacter. 2013;18 Suppl 1:39-43. doi: 10.1111/hel.12078. [PubMed: 24011244].

9. Amieva M, Peek RM. Pathobiology of Helicobacter pyloriInduced Gastric Cancer. Gastroenterology. 2016;150(1):64-78. doi: 10.1053/j.gastro.2015.09.004. [PubMed: 26385073].

10. Cover TL, Blanke SR. Helicobacter pylori VacA, a paradigm for toxin multifunctionality. Nat Rev Microbiol. 2005;3(4):320-32. doi: 10.1038/nrmicro1095. [PubMed: 15759043].

11. Ding SZ, Zheng PY. Helicobacter pylori infection induced gastric cancer; advance in gastric stem cell research and the remaining challenges. Gut Pathog. 2012;4(1):18. doi: 10.1186/1757-4749-4-18. [PubMed: 23217022].

12. Ford AC, Forman D, Hunt RH, Yuan Y, Moayyedi P. Helicobacter pylori eradication therapy to prevent gastric cancer in healthy asymptomatic infected individuals: systematic review and metaanalysis of randomised controlled trials. BMJ. 2014;348:g3174. doi 10.1136/bmj.g3174. [PubMed: 24846275].

13. Ford AC, Forman D, Hunt R, Yuan Y, Moayyedi P. Helicobacter pylori eradication for the prevention of gastric neoplasia. Cochrane Database Syst Rev. 2015;(7). CD005583. doi: 10.1002/14651858.CD005583.pub2. [PubMed: 26198377].

14. Malekzadeh R, Derakhshan MH, Malekzadeh Z. Gastric cancer in Iran: epidemiology and risk factors. Arch Iran Med. 2009;12(6):576-83. [PubMed: 19877751].

15. Naeimehossadat A, Tohid J, Seyyed MT. Area-to-area poisson kriging and spatial bayesian analysis in mapping of gastric cancer incidence in Iran. APJCP. 2016;17(10):4587. 